\title{
Linking genomic signatures of selection to expression variation and direct evidence of local
} adaptation

Nicholas Price, ${ }^{\mathrm{a}^{*}}$ Jack L. Mullen, ${ }^{\mathrm{a}}$ Junjiang Lin, ${ }^{\mathrm{a}}$ Christina Boucher ${ }^{\mathrm{b}}$, John K. McKay ${ }^{\mathrm{a}}$

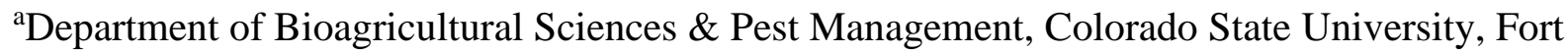
Collins, CO 80523, USA

8 bepartment of Computer and Information Science and Engineering, University of Florida, 9 Gainesville, FL 32611, USA

*Corresponding author:

13 Name: Nicholas Price

email: price4890@gmail.com

\section{Abstract}

Understanding how genomic and expression variation is linked to adaptation of plants to local environments is fundamental to the fields of evolutionary biology and species conservation. Using locally adapted Arabidopsis thaliana Italy and Sweden populations, we examine how variation in gene expression under control and cold acclimation conditions, is linked to allele frequency differentiation (AFD); linkage disequilibrium (LD); selective constraint at nonsynonymous sites; and genetic-tradeoff quantitative trait loci (GT-QTL). Our results indicate that contrary to genes showing a main effect in environment (E), expression genotype by environment interactions (GxE) show significantly higher AFD along cis-regulatory and nonsynonymous sites than the neutral expectation; and interestingly, highly differentiated GxE genes show higher expression and inter-species selective constraint than the rest of the genes.

27 When examining the association between genomic signatures of selection along GxE/E genes and GT-QTL, we find that GxE genes showing a high AFD and LD, display a significant and 
genes show a higher enrichment than the genome-wide control. In summary, our results suggest, that these highly expressed and selectively constrained GxE genes, may have been part of a coldresponsive regulon of E genes that experienced recent selection when migrating to new environments. Candidate GxE genes underlying GT-QTL reveal interesting biological processes acclimation, freezing tolerance, and response to hypoxia. Finally, we find no evidence linking lower expression of the CBF-dependent freezing tolerance pathway to genetic-tradeoffs and

37 adaptation to warmer climates.

\section{Introduction}

40 Populations may vary in genotype, phenotype, and fitness across geographical regions that differ

41 in abiotic variables of the environment. Such variation maybe generated after populations

42 become adapted to local climates, where local genotypes have higher fitness than foreign

45 local adaptation, since studies have linked it to increases in stress tolerance (Rockman, et al.

46 2003; López-Maury, et al. 2008; Thomashow 2010; Brown, et al. 2017), and the adjustment of

47 an organism's life-cycle to favorable environmental conditions (Seo, et al. 2009; Chiang, et al.

48 2011). Understanding the link between genetic, expression, and fitness variation under different

49 abiotic environments is central to the fields of evolutionary biology (Hoban, et al. 2016),

50 conservation genomics (Razgour, et al. 2019), and plant breeding (Henry and Nevo 2014). 
52 Gene expression responses under different environments, are often conserved between genotypes

53 from different populations (Hannah, et al. 2006; Des Marais, et al. 2012), in which case, they

54 will exhibit a main effect in environment (“E”) when plotted in a norm of reaction plot (Baye, et

55 al. 2011). On the contrary, they may exhibit genotype-by-environment interactions (“GxE”), in

56 which case the ranks of genotypes $(G)$ change or switch from one environment to another (Baye,

57 et al. 2011). E-genes may underlie adaptations to common environmental changes, while GxE-

58 genes may underlie adaptation to aspects of the environment that significantly differ between

59 locations within a specie’s range. For example, across the native range of a plant, all populations

60 may face a slight deviation in temperature during winter/summer which engages a similar

61 response among a set of genes of essential genes (i.e., E responses). On the other hand, parts of

62 the native range may experience much harsher winters/summers than on average, thereby

63 causing divergent selection between genotypes and the formation of GxE responses. If

64 expression GxE interactions reflect fitness GxE interactions, then they may represent a important

65 mechanisms of adaptation (López-Maury, et al. 2008; Franssen, et al. 2011; Morris, et al. 2014;

66 Lovell, et al. 2016).

68 Genetic variation linked to expression and fitness GxE interactions can exhibit: (a) genetic

69 tradeoffs, where the derived genotype is advantageous in one environment but deleterious in the

70 other; and (b) conditional neutrality where the derived genotype is advantageous (conditionally

71 advantageous) or deleterious (conditionally deleterious) in one environment and neutral in the

72 other (Anderson, et al. 2011; Mee and Yeaman 2019). Despite the presence of fitness GxE

73 interactions, instances of conditionally deleterious or more correctly non-locally maladaptive

74 mutations, do not represent instances of ‘adaptation’ (Mee and Yeaman 2019). To identity 
75 candidate genetic variation underlying local adaptation at the single nucleotide level, the two of

76 the main approaches used are: (a) identifying single nucleotide polymorphism (SNP) that show

77 significantly higher allele frequency differentiation between populations than expected under

78 neutral models of evolution (Beaumont and Balding 2004; Foll, et al. 2014; de Villemereuil and

79 Gaggiotti 2015) and (b) identifying alleles showing significant associations to environment while

80 accounting for population/geographic structure (Lasky, et al. 2012; Zhou and Stephens 2012;

81 Gunther and Coop 2013; Luu, et al. 2017; Caye, et al. 2019). Loci underlying genetic-tradeoffs

82 are expected to exhibit significantly stronger population genomic evidence of local adaptation

83 than the genome average and conditionally advantageous loci (Tiffin and Ross-Ibarra 2014;

84 Yoder and Tiffin 2017; Mee and Yeaman 2019).

86 Some of the main difficulties in identifying SNPs underlying local adaptation is disentangling

87 adaptive, from neutral or slightly deleterious variation generated by background/relaxed

88 selection, and genetic drift (Zhen and Ungerer 2008b; Hoban, et al. 2016; Matthey-Doret and

89 Whitlock 2019). Simulation studies comparing various methods used to identify genetic variation

90 underlying local adaptation while accounting for the effects of population structure have shown

91 that the power of each method can significantly change depending on the underlying

92 evolutionary scenario, in addition to other factors (De Mita, et al. 2013; de Villemereuil, et al.

93 2014; Lotterhos and Whitlock 2015; Yoder and Tiffin 2017). Furthermore, in examining the link

94 between GWA/population-genomic methods and empirical evidence of local adaptation, the

95 strength of this link changed depending on the method(s) used in studies (Fournier-Level, et al.

96 2011; Lasky, et al. 2014; Yoder, et al. 2014; Exposito-Alonso, et al. 2018; Price, et al. 2018;

97 Price, et al. 2020). 
Despite these hurdles, there have been many studies examining the genetic basis of local

100

101

102

103

104

105

106

107

108

109

110

adaptation (Savolainen, et al. 2013; Hoban, et al. 2016), but only a few linking genome-wide expression variation, sequence variation, and fitness variation across selective gradients (Kelly 2019). Among the few, a study by Lasky, et al. (2014) examined the link between genomic signatures of local adaptation, patterns of expression, and fitness variation in Arabidopsis. The main result of the study was that expression GxE genes showed a higher enrichment of climatecorrelated SNPs than genes showing a main effect in environment (E); suggesting a role of expression GxE interactions in local adaptation (Lasky, et al. 2014). Nonetheless, the enrichment of fitness associations along GxE genes was not significant despite being higher than $\mathrm{E}$ genes. This discordance could be the result of differences in purifying selection between $\mathrm{E}$ and $\mathrm{GxE}$ genes leading to an enrichment of slightly deleterious climate-associated SNPs in the latter set (Mee and Yeaman 2019).

Arabidopsis wild populations offer a valuable resource to re-examine the interplay between genetic, expression, and fitness variation across climatic conditions. The native range of Arabidopsis includes parts of Northern and Southern Europe that experience significantly different climatic conditions. For example, populations in North Sweden, experience average soil temperatures below freezing for about a 1/3 of the year, while in North-Central Italy such temperatures are rarely recorded (Oakley, et al. 2014). Reciprocal transplant experiments have showed strong adaptive differentiation between these populations and evidence of genetictradeoffs (Ågren and Schemske 2012; Ågren, et al. 2013). Among the traits suggested to underlie these genetic-tradeoffs, is freezing tolerance (Oakley, et al. 2014); and more specifically freezing 
121 tolerance variation associated with the CBF pathway (Thomashow 2010; Park, et al. 2015; Park,

122 et al. 2018). Studies have suggested that the lower freezing tolerance and expression of this

123 pathway (Cook, et al. 2004; Hannah, et al. 2006; McKhann, et al. 2008; Gehan, et al. 2015)

124 across Arabidopsis populations in warm climates (e.g., Italy), is an adaptive response that is

125 deleterious in cold climates (e.g., Sweden) (Oakley, et al. 2014). This adaptive response has been

126 linked to non-functionalization of the CBF-pathway (Oakley, et al. 2014; Gehan, et al. 2015;

127 Monroe, et al. 2016). Nonetheless this hypothesis has been disputed by studies showing that this

128 nonfunctionalization and decrease in freezing tolerance is due to relaxed selection in warmer

129 climates (Zhen and Ungerer 2008a, 2008b; Zhen, et al. 2011).

131 To re-examine the link between genetic, expression, and fitness variation of Arabidopsis

132 populations in different climates, and the role of the CBF-pathway in local adaptation to

133 temperature, the current study examines the following data: (a) re-sequenced genomes of locally

134 adapted (Ågren and Schemske 2012) South Italy and North Sweden (Price, et al. 2020); (b)

135 expression of Italy and Sweden genotypes under control and cold-acclimation conditions (Gehan,

136 et al. 2015); and (c) quantitative trait loci (QTL) explaining fitness variation of Italy and Sweden

137 recombinant inbred lines grown in a series of reciprocal transplant experiments (Ågren, et al.

138 2013). More specifically, we examine the link between allele frequency differentiation (AFD)

139 and linkage disequilibrium (LD) at cis-regulatory (sites found $1 \mathrm{~kb}$ upstream from the

140 transcriptional start site) and nonsynonymous sites, to patterns of expression ( $\mathrm{E}$ and $\mathrm{GxE}$ ) and

141 genetic-tradeoff QTL, while taking into account the effects of selective constraint (or purifying

142 selection) at nonsynonymous sites. Among population genomic signatures of local adaptation we 
143 chose AFD and LD, since these were previously found to be enriched along fitness QTL (Price,

144 et al. 2020).

145 Materials and Methods

146 Extraction of RNA under cold conditions and sequencing

147 The Arabidopsis SW and IT accessions were collected from their native habitats in Sweden and

148 Italy, respectively (Ågren and Schemske 2012). Plants were grown at $22^{\circ} \mathrm{C}$ on soil under a $12 \mathrm{~h}$

149 photoperiod for $18-26$ days (control), or at $4^{\circ} \mathrm{C}$ under a $12 \mathrm{~h}$ photoperiod for 1 or 2 weeks (cold

150 treatment). Rosette tissue was collected from plants exposed to low temperature $\left(4^{\circ} \mathrm{C}\right)$ for 0,1 ,

151 and 2 weeks. Total RNA was isolated for each experimental replicate (three replicates). Nine

152 replicates were collected for each accession, for a total of 18 biological replicates. Further details

153 can be found in the study by Gehan et al. (2015).

155 RNA was submitted for RNAseq library prep and 100bp single-end RNAseq analysis to

156 Michigan State University’s Research Technology Support Facility (RTSF). Sample preparation

157 was performed by MSU RTSF with standard protocols of the mRNA-Seq Sample Preparation

158 Kit (Illumina). Sequencing was performed on an Illumina Genome Analyzer II (Illumina). Three

159 samples were multiplexed in a lane for a total of 6 lanes. After quality trimming, RNAseq

160 resulted in single-end reads $\sim 75$ bp in length with an average of 45,257,092 reads passing the

161 Illumina purity filters for each sample. To map reads to the Arabidopsis thaliana genome we

162 used Tophat (Trapnell, et al. 2009) and we estimated transcript abundance using Cufflinks

163 (Trapnell, et al. 2010). 
To identify genes showing a main effect in environment (or condition) (E) and genotype by environment interactions (GxE) we used the we used the package DESeq2 (Love et al. 2014) and focused on expression after one week of cold. More specifically, using the function “DESeqDataSetFromMatrix” and a design to identify genotype by environment interactions (“genotype+condition+genotype*condition”) we identified GxE genes that showed an adjusted

171 p-value (“padj”) of $<0.01$. Thereafter, using the “contrast” argument we extracted genes that

172 showed a main effect in environment (E) using a padj <0.01. To ensure no main ffect in

173 genotype among E genes we removed any genes showing a main effect in genotype (G) using a p-value of 0.05 .

177 To compare average expression of Italy and Sweden plants across E and GxE genes we first estimated the average "Fragments Per Kilobase of exon model per Million mapped fragments”

$179(\overline{\mathrm{FPKM}})$ of the three samples under each pair of conditions (“control”, “cold”). Using the average expression of each gene under control and cold conditions, we estimated the mean expression and 95\% CI’s of all genes in each category (i.e., E and GxE genes). To estimate 95\%

182 CI's we used10,000 bootstrap samples. In addition to average expression of genes across each 183 condition, we also estimate average difference in expression between conditions $\left(\overline{\mathrm{FPKM}_{\text {cold }}}-\right.$ $184 \overline{\text { FPKM }}_{\text {control }}$ ). Selective constraint/ purifying selection at nonsynonymous sites was examined 185 using the ratio of nonsynonymous to synonymous rates of substitution (dN/dS). dN/dS ratios 186 were downloaded from EnsemblPlants (Howe, et al. 2020) Biomart (Kinsella, et al. 2011), using 187 Arabidopsis thaliana and Arabidopsis halleri orthologs. dN/dS ratios above 1 were ignored. 
Population genomic signals of selection

As population genomic signatures of local adaptation we used a combination absolute allele frequency differentiation $\left(\left|f_{N . S w e d e n}-f_{\text {S.Italy }}\right|\right)$ and linkage disequilibrium (LD) between a SNP and its neighboring SNPs with a 20kb window. LD was measured using the package 'PLINK' (Purcell, et al. 2007) and it was estimated as the mean square coefficient of correlation $\left(\overline{r^{2}}\right)$. AFD and LD were estimated in a previous study (Price, et al. 2020).

\section{Defining cis-regulatory and nonsynonymous variation}

Cis-regulatory sites of genes were defined using a maximum length of $1 \mathrm{~kb}$ from the transcriptional start site unless there was overlap with the transcribed region of another gene in which case the promoter region was shorter. For sites that were associated to two genes, were assigned to the nearest gene. To call nonsynonymous variation among Italy and Sweden accessions we used bi-allelic sites, a publicly available python script (callSynNonSyn.py; archived at https://github.com/kern-lab/), and gene models downloaded from the TAIR database (TAR10 genome release) (Berardini, et al. 2015).

\section{Circular permutation tests to examine evidence of local adaptation across groups of genes}

To examine whether the proportion of (E/GxE) genes with cis-regulatory/nonsynonymous SNPs showing evidence of local adaptation (estimated using AFD and/or LD) is significantly higher than expected by chance we used a circular permutation test. This test has been previously explained in detail (Price, et al. 2020); but in brief, AFD’s and/or LD’s are shifted across the genome (not randomly shuffled) and according to certain criteria (e.g., AFD>0.60) we estimate the proportion of genes with high AFD and/or LD cis-regulatory/nonsynonymous SNPs. This 
212 was repeated a thousand times and the resulting permutation distribution is compared to the

213 observed proportion/number of genes with high AFD.

Assembling CBF-regulon genes and flowering time estimates

216 Genes predicted to be regulated by the three CBF transcription factors (CBF's 1-3) were

217 retrieved from Park, et al. (2018) resulting in a set of 476 genes. Estimates of flowering time for

218835 Eurasian A. thaliana accessions were downloaded from the study by Alonso-Blanco et. al

219 (2016) (1001 Genomes Consortium 2016).

\section{Results}

Sweden but not Italy plants show significant upregulation of GxE genes under cold

224 To examine gene expression in Italy and Sweden plants under control $\left(22^{\circ} \mathrm{C}\right)$ and cold

225 conditions $\left(4^{\circ} \mathrm{C}\right)$ we used DESeq2 (Love, et al. 2014). Using an FDR of $<0.01$, we identified

226392 that showed genotype by environment interactions (“GxE”), and 2, 883 that showed a main

227 effect in environment (“E”) after removing genes that showed a main effect in genotype at a p-

228 value $<0.05$. To compare mean expression of these genes between Italy and Sweden plants we

229 estimated mean Fragments Per Kilobase Of Exon Per Million Fragments Mapped $\left(\overline{F P K M} \times 10^{-3}\right)$

230 under control and cold conditions and determined the 95\% CI’s using a bootstrap approach

231 (Figures 1a \& 1b). As expected, mean expression of "E” genes under control and cold conditions

232 was identical in Italy and Sweden plants (Figure 1a). On the other hand, mean expression of

233 “GxE” genes was significantly different between Italy and Sweden plants under cold conditions

234 (Figure 1b); with Sweden plants showing a significant upregulation of genes when compared to 235 control conditions $\left(\overline{\mathrm{FPKM}_{\text {cold }}}-\overline{\text { FPKM }_{\text {control }}}>0\right)$ (Figure 1c). On the contrary, Italy plants 
236 showed a decrease in expression under cold conditions when compared to control conditions

$237\left(\overline{\text { FPKM }_{\text {cold }}}-\overline{\text { FPKM }_{\text {control }}}<0\right)$ (Figure 1c).

238

(a)

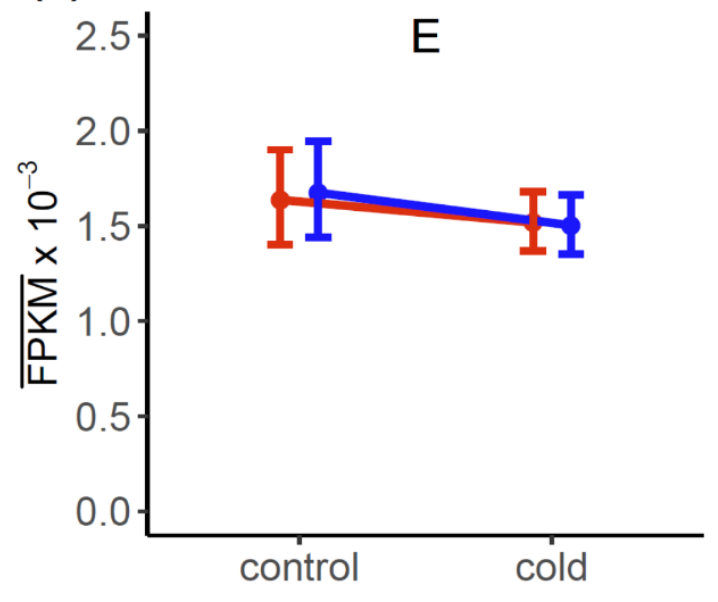

(c)

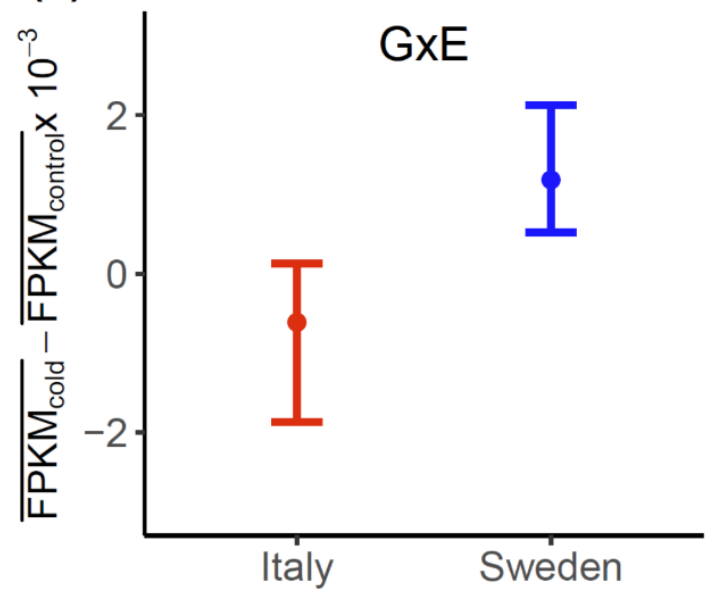

(b)

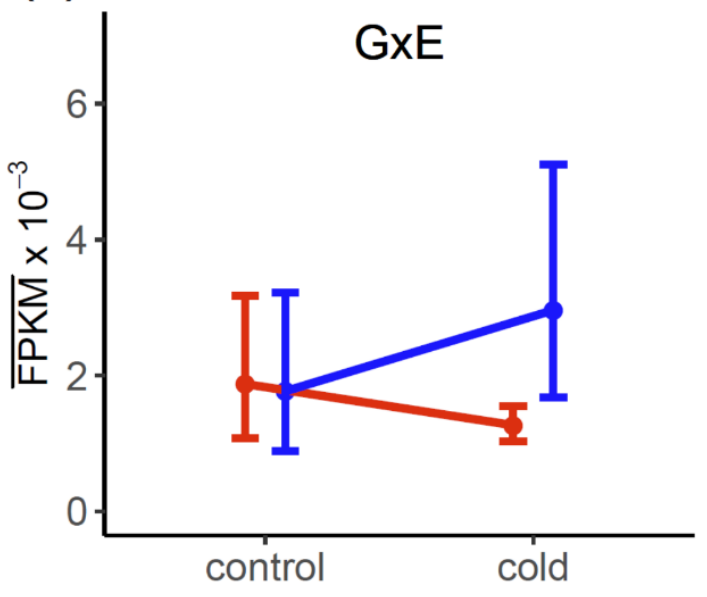

(d)

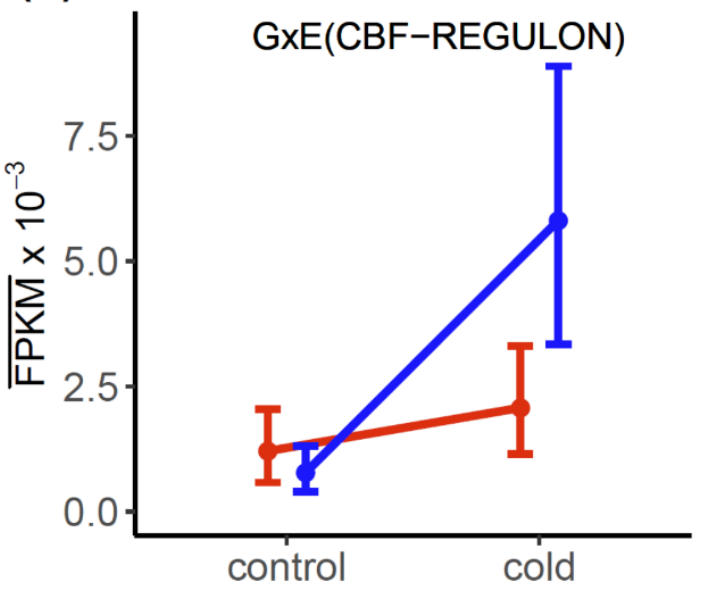

240 Figure 1. (a-b) Mean expression $\left(\overline{F P K M} \times 10^{-3}\right)$ of $\mathrm{E}$ and $\mathrm{GxE}$ genes under control and cold 241 conditions (FPKM: Fragments Per Kilobase Of Exon Per Million Fragments Mapped). Shown

242 are the means and 95\% confidence intervals estimated using a bootstrap approach. Mean

243 expression of Sweden plants under cold conditions was significantly higher than in Italy plants

244 (c) In comparison to control conditions $\left(\overline{\mathrm{FPKM}_{\text {cold }}}-\overline{\mathrm{FPKM}_{\text {control }} \mathrm{x}} 10^{-3}\right)$ Sweden plants showed 245 a net upregulation ( $>>0)$ under cold, while Italy plants showed a net downregulation $(<<0)(d)$ 246 Despite the opposite trends (c), mean expression of CBF-regulon GxE genes in Italy and Sweden 
247 plants, was higher under cold than control conditions; with Sweden plants showing the largest

248 increase ( $>2$ times higher).

250 To examine whether this decrease was also present among known freezing tolerance genes we

251 examined mean expression of 53 CBF-regulon genes that showed GxE interactions. As shown in

252 Figure 1d, expression of GxE CBF-regulon genes was significantly higher under cold than

253 control conditions, in both Italy and Sweden plants. The increase in Sweden plants, however,

254 was twice as high than in Italy plants. Among the set of 476 CBF-regulon genes (Park, et al.

255 2018), we identified 23 “E” genes and 53 “GxE” genes. In comparison to the total number of "E”

256 and “GxE” genes (E: 2883, GxE: 392) CBF-regulon genes showed a significant enrichment (p-

257 value $<0.01$ ) in GxE interactions according to single tail fisher’s test ("fisher.test" implemented in $258 \mathrm{R})$.

GxE but not E genes show significant allele frequency differentiation at cis-regulatory and

262 Loci underlying local adaptation are expected to show significant allele frequency (Tiffin and

263 Ross-Ibarra 2014) between populations. To examine such evidence along E and GxE genes, we

264 looked at allele frequency differentiation at cis-regulatory and nonsynonymous SNPs. As a

265 measure of allele frequency differentiation we used absolute allele frequency difference of the

266 non-reference allele between Italy and Sweden populations (AFD: $\left|f_{\text {N.Sweden }}-f_{\text {S.Italy }}\right|$ ) (Berner

267 2019; Price, et al. 2020); which showed a strong correlation ( $\mathrm{R}^{2}: 0.96$, Figure S1) with a two

268 population, two allele, Fst measure (Bhatia, et al. 2013). 
Along candidate cis-regulatory sites, the observed proportion of E genes (Figure 2a) with Cis-

271 regulatory SNPs showing different levels of AFD's (AFD<0.40, AFD>0.60, 0.80) did not

272 significantly differ than the expected proportion (Figure 2a). On the other hand, the proportion of

273 GxE genes with cis-reg. SNPs showing low AFDs $(<0.40)$ was significantly lower than the

274 expectation, while the proportion associated with high AFD’s $(>0.60,0.80)$ was significantly

275 higher (Figure 2a). The difference in AFD’s along cis-regulatory SNPs can also be seen when 276 comparing the histograms of $\mathrm{E}$ and GxE genes. As shown in Figure 2b, GxE genes show a higher

277 proportion of cis-reg. SNPs with high AFD’s (>0.60) than E genes. The two histograms were 278 found to be significantly different according to a $X^{2}$ test $(X$-squared $=25.177, \mathrm{df}=9$, $\mathrm{p}$-value $=$ $2790.0028)$.
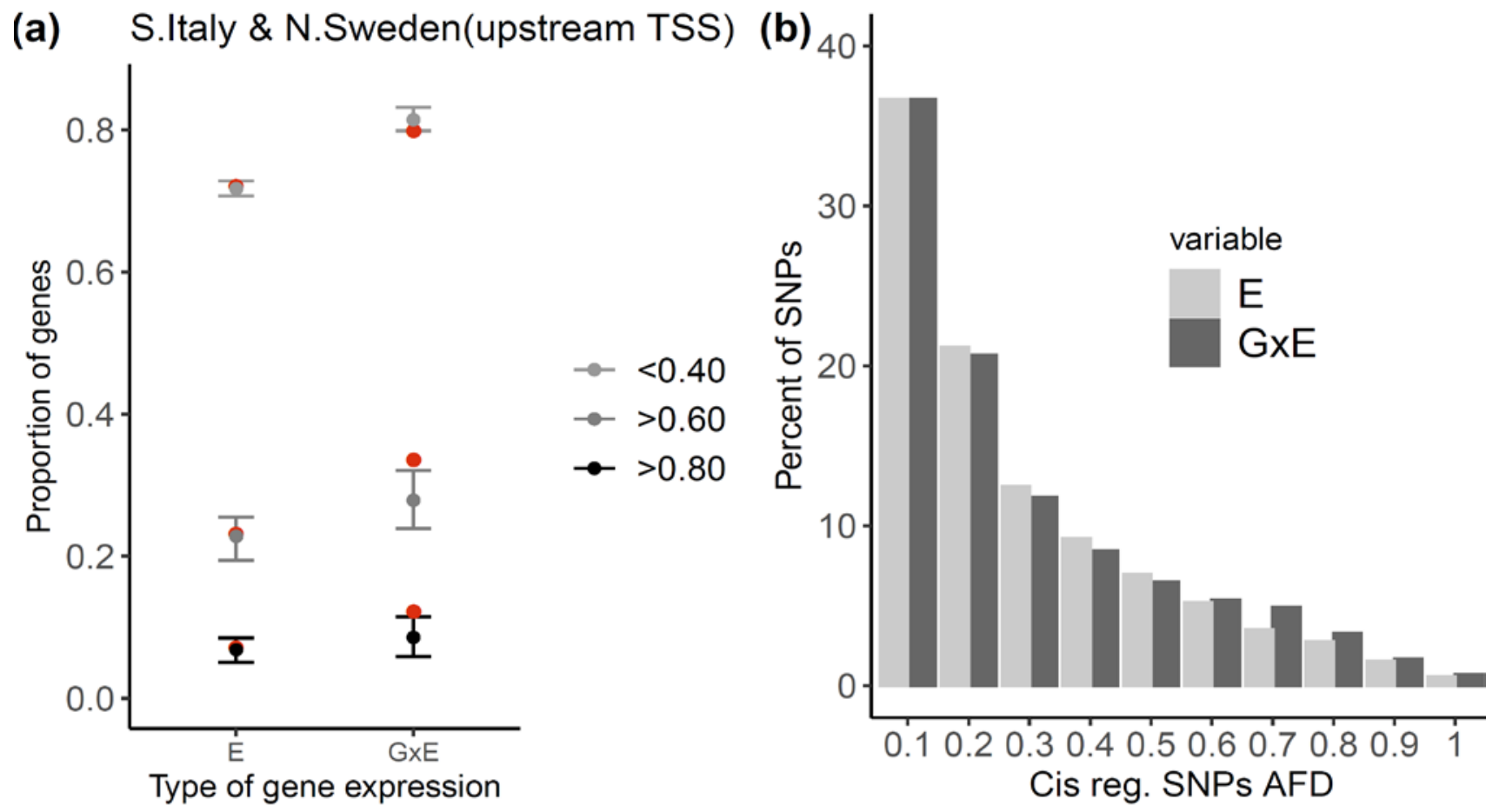

281 Figure 2. (a) The proportion of GxE genes showing high allele frequency divergence (AFD) at 282 cis-regulatory sites was significantly higher than the expectation derived using circular 283 permutations of genome wide SNPs. E genes on the other hand, showed no significant genetic 284 differentiation along these sites. (b) The significantly higher differentiation is also observed 
285 when comparing the AFD distributions along cis-regulatory sites of $\mathrm{E}$ and GxE genes (X-squared $286=25.177, \mathrm{df}=9$, p-value $=0.0028)$. GxE genes show a higher proportion of cis-regulatory SNPs 287 with an AFD $>0.60$.

289 To test whether nonsynonymous variation across "E” and/or “GxE” genes showed evidence of 290 local adaptation we compared AFD distributions of nonsynonymous and synonymous variation.

291 As depicted in Figure 3a, the distribution of AFD’s at nonsynonymous and synonymous sites of 292 “E” genes is not significantly different according to a $X^{2}$ test ( $X^{2}$ : 11.0, df:9, p-value: 0.28).

293 Contrary to "E” genes, the distribution of AFD’s at nonsynonymous sites of “GxE” genes was 294 significantly different ( $\mathrm{X}^{2}:$ 18.5, df: 9, p-value: 0.03$)$ than synonymous sites (Figure 3b). More 295 specifically, nonsynonymous sites across “GxE” genes showed an enrichment in low AFD’s and 296 high AFD’s (Figure 3b) which can be caused by recent local adaptation and/or purifying 297 selection (Nielsen 2005).
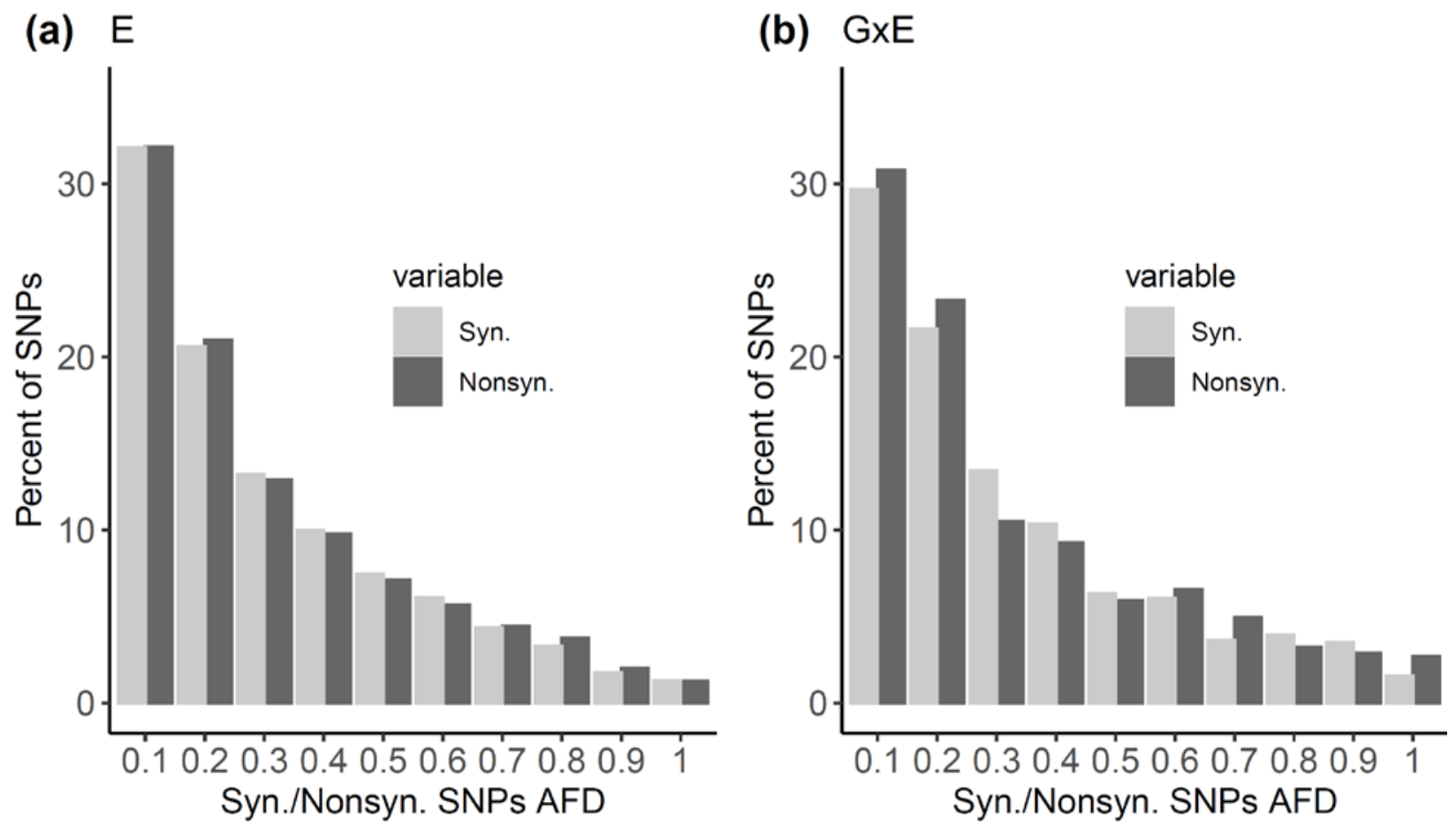
299 Figure 3. (a) Allele frequency divergence (AFD) between synonymous and nonsynonymous

300 sites of E genes did not significantly differ according to a X2 test $(\mathrm{X}$-squared $=11.002$, $\mathrm{df}=9$, $\mathrm{p}$ -

301 value $=0.28$ ). (b) When comparing AFD between synonymous and nonsynonymous sites of GxE

302 genes identifies a statistical significance $(\mathrm{X}: 18.546 \mathrm{df}=9$, $\mathrm{p}$-value $=0.029)$. The proportion of

303 nonsynonymous SNPs with AFD’s $<0.2$ and $>0.6$ was higher than synonymous sites. Such

304 deviations could be caused by both recent selection and purifying selection.

305

Contrasting patterns of expression and purifying selection between GxE and E genes exhibiting

307 low and high $A F D$

308 Variation in allele frequency differentiation between nonsynonymous sites of genes can result

309 from differences in purifying selection, in addition to local adaptation. Furthermore, these

310 differences could be associated with variation in gene expression among genes. To examine the

311 link between AFD, purifying selection, and expression we first split E and GxE genes into ones

312 that showed an AFD>0.60 at least one cis-regulatory/nonsynonymous site (AFDhigh) and ones

313 that did not (AFDlow); furthermore, we narrowed down the sets of genes to those that we had

314 estimates of $\mathrm{dN} / \mathrm{dS}$ (dN: rate of nonsynonymous substitutions per site; $\mathrm{dS}$ : rate of synonymous

315 substitutions per site); a measure of purifying selection at nonsynonymous sites. 
(a)

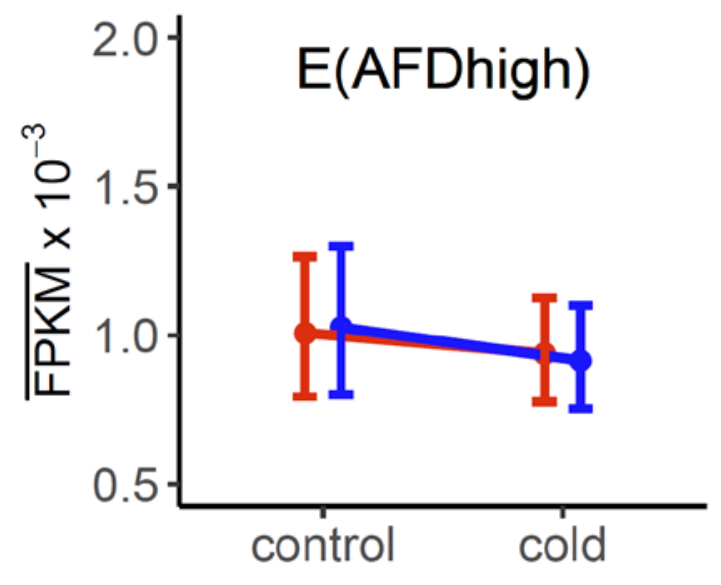

(c)

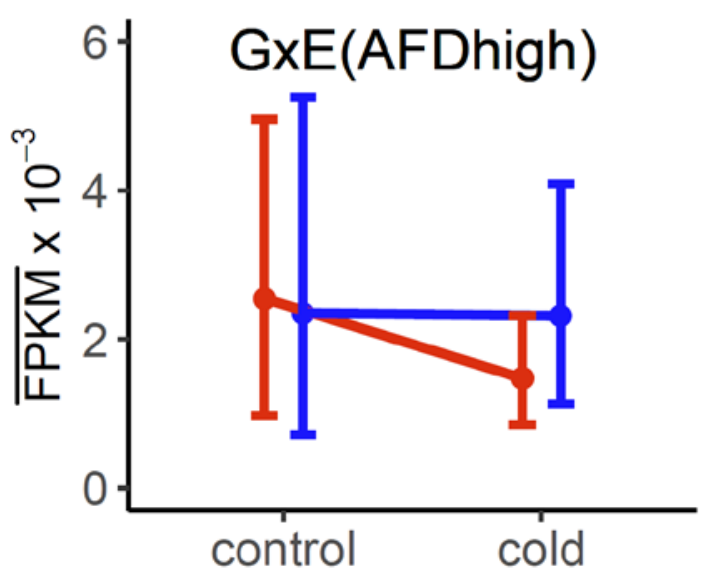

(b)

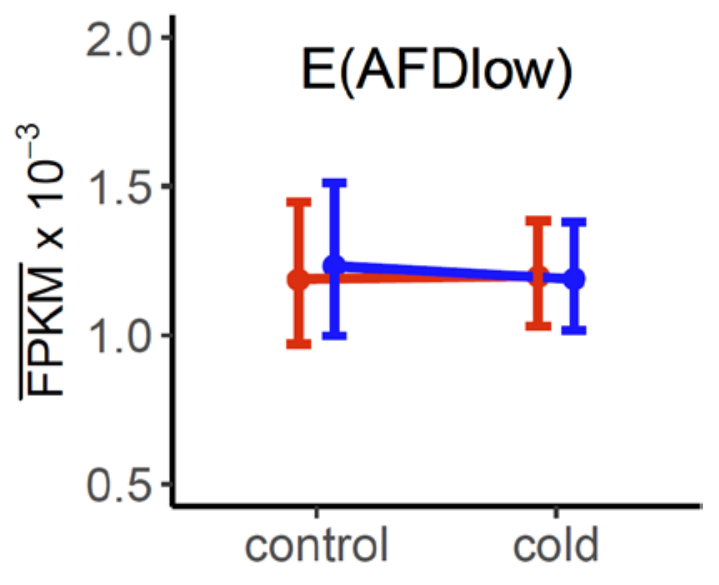

(d)

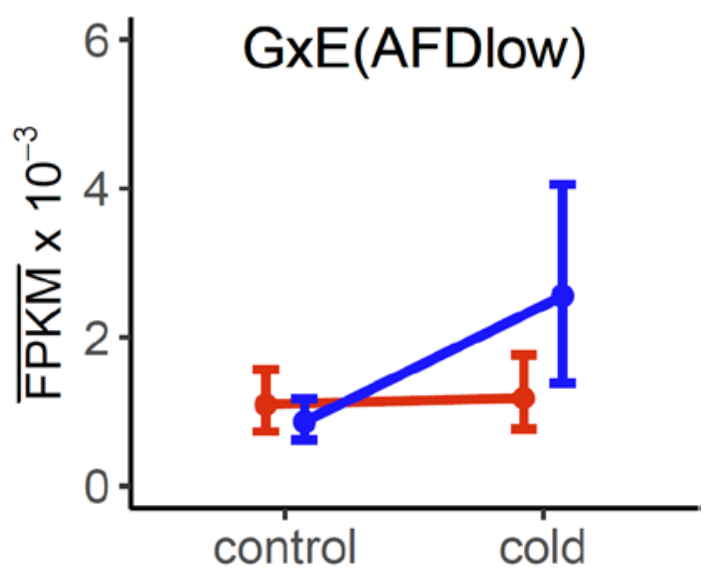

Figure 4. (a-b) E genes with at least one nonsynonymous/cis-regulatory SNP showing an AFD>0.6 (AFDhigh) were expressed at significantly lower levels when compared to the rest of the E genes with SNPs at cis-regulatory/nonsynonymous sites (AFDlow). Mean expression $\left(\overline{F P K M} \times 10^{-3}\right)$ of AFDhigh E genes across ecotypes and conditions was $\approx 1$, while that of AFDlow E genes was $>>1$. (c-d) On the other hand, AFDhigh GxE genes showed a higher mean expression $\left(\approx 2.13 \overline{F P K M} \times 10^{-3}\right)$ across ecotypes and conditions than AFDlow GxE genes $(\approx$ $1.47 \overline{F P K M} \times 10^{-3}$.

E genes with high AFD SNPs showed a mean $\overline{F P K M} \times 10^{-3}$ of $\approx 1$ across all conditions and ecotypes, while E genes with low AFD showed an $\overline{F P K M} \times 10^{-3}$ significantly higher than 1 
327 (Figures 4a-4b). The opposite trend was seen across GxE genes. GxE genes with low AFD SNPs

328 showed significantly lower expression $\left(\approx 1.47 \overline{F P K M} \times 10^{-3}\right)$ across the two conditions and

329 ecotypes, than GxE genes with high AFD SNPs $\left(\approx 2.13 \overline{F P K M} \times 10^{-3}\right)$ (Figures 4c-4d). In

330 association with the levels of expression we observed a change in patterns of selective

331 constraint/purifying selection along protein coding genes. As shown in Figure 5, E genes that

332 contained high AFD SNPs, and were expressed at lower levels than AFDlow E genes, also

333 showed a higher $\mathrm{dN} / \mathrm{dS}$, which translates to lower levels of purifying selection. On the other

334 hand, AFDhigh GxE genes showed higher expression than AFDlow GxE genes, and a lower

$335 \mathrm{dN} / \mathrm{dS}$ (Figure 5).

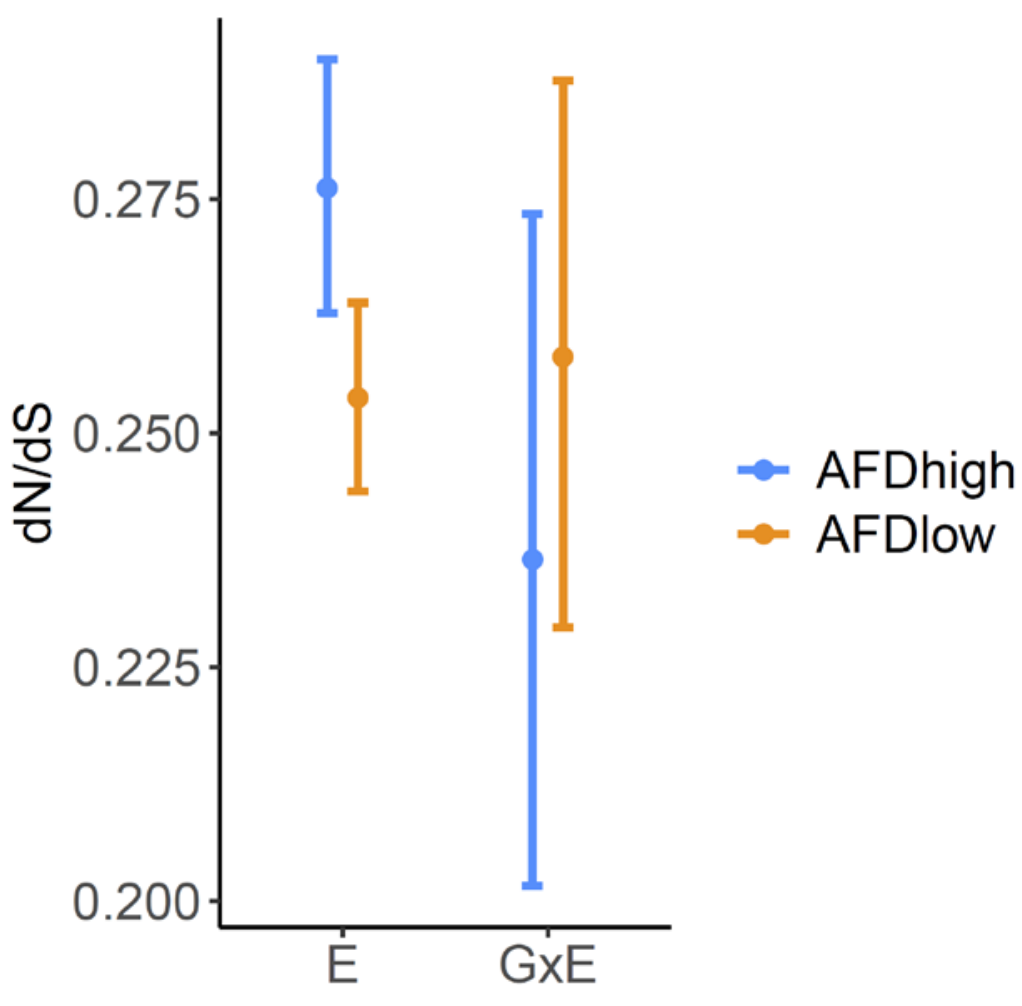

338 Figure 5. Patterns of purifying selection differed significantly between GxE and E genes that 339 showed different levels of allele frequency divergence (AFD) at nonsynonymous sites/cis- 
regulatory sites. E genes with high AFD SNPs (AFDhigh) showed significantly lower purifying selection (higher $\mathrm{dN} / \mathrm{dS}$ ) at nonsynonymous sites, than E genes with low AFD SNPs (AFDlow) and GxE genes with high AFD SNPs (AFDhigh). GxE genes with high AFD SNPs also showed a lower $\mathrm{dN} / \mathrm{dS}$ than GxE genes with low AFD SNPs. These patterns of $\mathrm{dN} / \mathrm{dS}$ seem to correlate with the level of expression associated with these genes (Figure 4). The ration dN/dS was estimated using pairs of A. thaliana and A. halleri orthologous genes.

\section{Significant evidence linking GxE genes to recent selection and genetic tradeoffs}

So far, we have showed that GxE genes showed significantly higher genetic differentiation than E genes at both cis-regulatory and nonsynonymous sites, in addition to higher levels of expression and purifying selection (Figures 2-5). To examine the association of E and GxE genes to fitness variation of Italy and Sweden genotypes at native sites, we used a set of 20 fitness QTL that were previously assembled into six genetic trade-off QTL that spanned $18.6 \mathrm{Mbs}$ of the genome (Ågren, et al. 2013). More specifically, we examined the distribution of genes showing high allele frequency differentiation (AFD) and linkage disequilibrium (LD) along genetic tradeoff QTL.

As shown in Table 1, in most instances the proportion of E genes withing genetic-tradeoff QTL was significantly higher than the genome-wide proportion; even when not filtering for high AFD and LD. On the other hand, GxE genes did not show any significant enrichment when not filtering for a high LD (Table 1). On the other hand, when we filtered for a high AFD (>0.60) and LD $(>019,0.32)\left(0.32\right.$ represents the $99^{\text {th }}$ percentile of the genome wide distribution of LD) the proportion of GxE genes along genetic-tradeoff QTL was significantly higher than the genome-wide proportion and the proportion of E genes satisfying these criteria (Table 1). In 
addition to examining the proportions along the six genetic tradeoff QTL, we also examined the

proportions of these genes within 100kb of fitness QTL peaks (Table S1). The only significant genes, and E genes (Table S1).

TABLE 1. Comparing the proportion $E$ and $G x E$ genes exhibiting different signatures of local

371 adaptation and selection, and found within six genetic tradeoff (GT) QTL peaks explaining

372 fitness variation between Italy and Sweden populations (Ågren, et al. 2013). The table splits a set

373 of genome-wide, E, and GxE genes according to their location along GT QTL and signatures of

374 selection (AFD: Allele frequency divergence \& LD: Linkage disequilibrium). The odd ratios

375 depicted are derived by comparing the proportion of E/GxE genes to the genome-wide set of

376 genes. A significantly higher proportion relative to the genome-wide set is indicated by a *, and

377 significantly higher proportion when comparing $\mathrm{E}$ and GxE genes is indicated by a $†$.

378 Comparison of proportions was done using a fisher's one-tail test $(\mathrm{p}$-val $<0.05)$ implemented in $\mathrm{R}$

379 ("fisher.test”).

\begin{tabular}{|c|c|c|c|c|c|c|c|c|}
\hline & & N-QTI & & GT-QTL & & & & GxE \\
\hline & $\begin{array}{l}\text { Genome- } \\
\text { wide }\end{array}$ & E & GxE & $\begin{array}{l}\text { Genome- } \\
\text { wide }\end{array}$ & E & GxE & ratio) & ratio) \\
\hline No filtering & 24253 & 2166 & 305 & 5725 & 624 & 74 & $1.22 * \dagger$ & 1.03 \\
\hline AFD $>0.60$ & 9082 & 734 & 128 & 2343 & 246 & 31 & $1.30 * \dagger$ & 0.94 \\
\hline $\begin{array}{l}\text { AFD }>0.60 \& \\
L D>0.19\end{array}$ & 1209 & 105 & 11 & 419 & 49 & 11 & $1.35^{*}$ & $2.88 * \dagger$ \\
\hline $\begin{array}{l}\text { AFD }>0.60 \& \\
\text { LD }>0.32\end{array}$ & 192 & 22 & 0 & 71 & 9 & 6 & 1.10 & Inf*† \\
\hline
\end{tabular}


382 To identify potential candidates underlying genetic tradeoffs, we chose GxE genes with cis-

383

384

385

386

387

388

389

390

391

392

393

394

395

396

397

398

399

400

401

regulatory/nonsynonymous SNPs with high AFD ( $>0.60)$ and LD ( $>0.19)$ (Table 2). As shown in

Table 2, GxE genes within genetic tradeoff QTL showed twice the expression levels than GxE

genes outside the QTL. Two of these genes (AT2G35050, FLDH) were previously identified as

candidate genes (Price, et al. 2018; Price, et al. 2020) and four of the genes (AT2G35050,

AT3G56408, AT4G33180, AT5G65860) have no known function. The rest of the genes have

been associated with some very interesting biological processes, such as shade avoidance, light-

dependent cold tolerance, drought and freezing tolerance, and response to hypoxia (Table 2).

COL7 which is located within genetic tradeoff QTL 1:3, is also located within a high confidence

flowering time QTL (Chr1: 27.4-29.1 Mb) where the Sweden genotype showed significantly

longer flowering time than the Italy genotype in Italy (Ågren, et al. 2017). As shown in the

rooted COL7 tree (Figure S2) Eurasian accessions with a similar sequence at the Swedish

genotype flo wer significantly later, than accessions with sequences as the Italy genotype.

TABLE 2. Genes showing significant genetic differentiation (AFD>0.60) and linkage

disequilibrium (LD>0.19,0.32) along genetic tradeoff (GT) QTL (ID’s shown from Ågren, et al. 2013). Shown is also the mean expression $\left(\overline{F P K M} \times 10^{-3}\right)$ of these genes under control (Ct. -22 ${ }^{\circ} \mathrm{C}$ ) and cold acclimation conditions (Cl.- $\left.4{ }^{\circ} \mathrm{C}\right)$. $\dagger$ indicates genes with cis-reg./nonsyn. SNPs with an $\mathrm{AFD}>0.60$ and $\mathrm{LD}>0.32$ ). The Biological process were taiken from the TAIR database (Berardini, et al. 2015).

\begin{tabular}{|l|l|l|l|l|l|l|}
\hline & GT & \multicolumn{2}{|l|}{ Italy } & \multicolumn{2}{l|}{ Sweden } & Biological processes \\
\cline { 3 - 6 } $\begin{array}{l}\text { Gene ID's (common } \\
\text { names) }\end{array}$ & QTL & Ct. & Cl. & Ct. & Cl. & \\
& ID & & & & & \\
\hline
\end{tabular}




\begin{tabular}{|c|c|c|c|c|c|c|}
\hline $\begin{array}{l}\text { AT1G73870 } \\
\text { (COL7) }\end{array}$ & $1: 3$ & 0.85 & 1.42 & 0.88 & 0.63 & $\begin{array}{l}\text { positive regulation of } \\
\text { transcription, secondary shoot } \\
\text { formation, shade avoidance }\end{array}$ \\
\hline AT2G35050† & $2: 2$ & 3.00 & 1.41 & 2.71 & 2.03 & Unknown \\
\hline $\begin{array}{l}\text { AT2G36530 } \\
\text { (LOS2) }\end{array}$ & $2: 2$ & 6.22 & 23.55 & 8.40 & 18.84 & $\begin{array}{l}\text { Involved in light-dependent cold } \\
\text { tolerance, glycolytic process, } \\
\text { response to abscisic acid, } \\
\text { cadmium ion, cold, light stimulus }\end{array}$ \\
\hline AT2G36580 & $2: 2$ & 0.94 & 2.54 & 1.24 & 1.70 & $\begin{array}{l}\text { cellular response to hypoxia, } \\
\text { glycolytic process }\end{array}$ \\
\hline $\begin{array}{l}\text { AT2G36830 } \\
(\text { GAMMA-TIP) } \dagger\end{array}$ & $2: 2$ & 2.16 & 1.48 & 2.22 & 0.50 & $\begin{array}{l}\text { Response to salt stress, gibberellic } \\
\text { acid mediated signaling pathway, } \\
\text { hydrogen peroxide, urea, and } \\
\text { water transport }\end{array}$ \\
\hline AT3G56408 & $3: 3$ & 0.44 & 0.22 & 0.15 & 0.22 & Unknown \\
\hline AT4G33180† & $4: 2$ & 0.16 & 0.07 & 0.14 & 0.19 & Unknown \\
\hline $\begin{array}{l}\text { AT4G33360 } \\
(\mathrm{FLDH}) \dagger\end{array}$ & 4:2 & 0.37 & 0.42 & 0.06 & 0.02 & $\begin{array}{l}\text { farnesol metabolic process, } \\
\text { negative regulation of abscisic } \\
\text { acid-activated signaling pathway }\end{array}$ \\
\hline $\begin{array}{c}\text { AT4G33470 } \\
(\text { HDA14) } \dagger\end{array}$ & $4: 2$ & 0.86 & 0.60 & 0.48 & 0.55 & $\begin{array}{l}\text { negative responses to salinity } \\
\text { stress, tubulin deacetylation }\end{array}$ \\
\hline $\begin{array}{l}\text { AT5G62530 } \\
(\mathrm{P} 5 \mathrm{CDH}) \dagger\end{array}$ & $5: 5$ & 0.66 & 1.45 & 1.05 & 1.01 & $\begin{array}{l}\text { Drought and freezing tolerance, } \\
\text { proline catabolic process to } \\
\text { glutamate, reactive oxygen } \\
\text { species metabolic process, } \\
\text { response to salt stress }\end{array}$ \\
\hline \multirow[t]{3}{*}{ AT5G65860 } & $5: 5$ & 0.15 & 0.42 & 0.22 & 0.31 & Unknown \\
\hline & QTL & 1.44 & 3.05 & 1.60 & 2.36 & \\
\hline & $\begin{array}{l}\text { NON } \\
- \\
\text { QTL }\end{array}$ & 0.6 & 1.03 & 0.44 & 1.06 & \\
\hline
\end{tabular}


instances of genetic tradeoffs but removes instances conditional neutrality where linkage disequilibrium is expected to be weaker but nonetheless higher than the neutral expectation. To

411 test whether conditional neutrality is linked to the lower expression of some GxE genes in Italy

412 (Figure 4c), we removed the genes in Table 2 from the set of high AFD GxE genes, and tested

413 whether there was a significant difference in LD between 89 genes where Italy plants showed

414 lower expression than Sweden plants under cold, and the rest of the 48 genes. Mean LD of these

415 sets of genes was approximately the same (LD 0.09), and not significantly different than the

416 genome average (LD 0.06), at cis-regulatory and nonsynonymous SNPs of $\mathrm{LD}<0.19$. In

417 addition to just choosing genes with a lower expression in Italy, we also looked at LD across

418 genes where Italy plants showed lower or equal to half the expression of Sweden plants under

419 cold. This resulted in 21 (out of the 89) genes, that also showed approximately the same LD

$420 \quad(\sim 0.09)$.

421

422 To further examine the possible role of the CBF pathway in causing genetic-tradeoffs we

423 examined the proportion of CBF-regulon genes with high AFD, or high AFD and LD, cis-

424 regulatory/nonsynonymous SNPs within genetic tradeoff QTL (Table S2). Relative to the

425 genome-wide set of genes none of the categories examined showed a significant enrichment

426 along the QTL (Table S2). In addition to CBF-regulon genes, we also examined whether the

427 genomic region that included the three CBF transcription factors (CBF1-3), showed any genetic

428 differentiation. Using a sliding-window approach we examined the proportion of high AFD

429 (>0.60) SNPs along these genes (Figure S3). The proportion of high AFD SNPs across these

430 genes was below the genome average (Figure S3). Under the assumption of genetic-tradeoffs we

431 would expect these regions to show a significant increase in allele frequency differentiation 
432 (Tiffin and Ross-Ibarra 2014). Furthermore, we did not find any significant evidence for recent

433 selection, since 19 cis-regulatory (no nonsynonymous SNPs) SNPs of the three CBF genes

434 showed a very low mean LD ( 0.05).

436 Discussion

437 The current study re-examines the link between genome-wide sequence and expression variation

438 to fitness variation of Arabidopsis populations showing significant evidence of local adaptation

439 in their native environments (Ågren and Schemske 2012; Ågren, et al. 2013). The enrichment of

440 genes showing a main effect in environment (E) along the low-resolution fitness QTL, in

441 combination with the even higher enrichment of GxE genes showing significant genetic

442 differentiation and linkage disequilibrium, suggest that plastic responses play an important role

443 in adaptation. More specifically, E genes may represent regulon of genes that are necessary for

444 facing common environmental challenges, while GxE genes represent instances of loci that

445 underwent divergent evolution to adapt to extreme environmental differences. Furthermore, our

446 results suggest that local adaptation occurs through highly expressed and selectively constraint

447 genes. Finally, we find no significant evidence linking significantly lower expression of the

448 CBF-pathway, to adaptation to warmer climates.

450 Local adaptation is expected to cause allele frequency differentiation (AFD) between

451 populations; especially in the case of genetic tradeoffs (Tiffin and Ross-Ibarra 2014).

452 Furthermore, if local adaptation is recent, loci should also exhibit high linkage disequilibrium

453 (LD) (Nosil, et al. 2009). The importance of these signatures were shown in a previous

454 Arabidopsis study (Price, et al. 2020), where we found that high AFD and LD SNPs were 
455 enriched along fitness QTL, and genes involved in life-history traits that are thought to play a

456 major role in local adaptation; such as flowering time. One of these genes (PIF3) showed

457 significant evidence of local adaptation in an evolutionary distant species of tree (Populus

458 balsamifera L.) (Keller, et al. 2012). In the current study, we find that expression GxE genes

459 with high AFD and LD SNPs are significantly enriched along individual fitness QTL and paired

460 genetic tradeoff QTL, providing strong evidence for their possible role in local adaptation.

461 Candidate GxE genes were tied to interesting biological processes such as: flowering time, light-

462 dependent cold acclimation, freezing tolerance, and response to hypoxia.

463

464 Our final set of GxE genes with high AFD and LD did not show any significant differences in

465 mean expression between Italy and Sweden (Table 2). On the other hand, high AFD GxE genes

466 with lower $\mathrm{LD}(\mathrm{LD}<0.19)$ showed large decreases in mean expression under cold in Italy plants

467 (Figure 4C). These genes, however, did not show any enrichment along genetic-tradeoff QTL,

468 and significant increases in LD. Some of the factors that may contribute to this observation, are

469 that some of these expression interactions are neutral/nearly-neutral, or they involve adaptive

470 mutations of small effect size (Yeaman 2015; Hoban, et al. 2016; Forester, et al. 2018; Mee and

471 Yeaman 2019).

472

473 Among the set of genes showing no significant evidence of local adaptation were the tree

474 freezing tolerance CBF transcription factors and CBF-regulon genes exhibiting GxE interactions.

475 Among the GxE-CBF-regulon genes with cis-regulatory/nonsynonymous SNPs (51/53), only

$47620 \%$ contained high AFD SNPs (>0.60), which is similar to the proportion observed by E genes

477 (Figure 2a). Furthermore, high AFD and/or LD GxE-CBF-regulon genes did not show significant 
478

479

480

481

482

483

484

485

486

487

488

489

490

491

492

493

494

495

496

497

498

499

500

enrichment along genetic-tradeoff QTL (Table S2). Finally, we did not find any significant evidence of local adaptation (i.e., in AFD and/or LD) along the three CBF transcription factors, supporting evidence that lower expression of these genes in warmer climates is under relaxed (Zhen and Ungerer 2008b; Zhen, et al. 2011) and not positive selection (Monroe, et al. 2016). It will be quite surprising if there is a unique genomic signature of adaptation underlying the three CBF genes, since high AFD and LD SNPs were enriched along the same genetic tradeoff QTL (GT QTL 4:2) but in a different region (Price, et al. 2020).

Interestingly, we find that GxE genes showing evidence of adaptation, show high expression and selective constraint/purifying selection—a pattern observed in other species (Wollenberg Valero, et al. 2014; Maddamsetti, et al. 2017; Boissot, et al. 2020). An interesting hypothesis that could be tested in future studies using Crispr-Cas9 technology (Cong, et al. 2013), is whether the effect size of candidate adaptive variation is positively correlated with levels of expression and selective constraint. This is partially supported by our study, since genes underlying the small number of high effect size QTL (Table 2) show higher mean expression than other genes. Unfortunately, we could not compare selective constraint between genes in Table 2 and the genome average given the very small sample of genes $(n=9)$ with orthologs in A. halleri.

In conclusion, our study shows how genomic signatures of local adaptation, recent selection, and selective constraint, are linked to expression and fitness variation between Italy and Sweden ecotypes. Temperature is one of the environmental variables that may underlie local adaptation underlying Arabidopsis populations, therefore, examining more variables (e.g., precipitation (Postma, et al. 2016; Exposito-Alonso, et al. 2018; Monroe, et al. 2018)) may help us further 
501 understand the genetic architecture of local adaptation (Dittmar, et al. 2016) and the selection

502 forces underlying it.

503

504

505

506

507

508

509

510

511

512

513

514

515

516

517

518

519

520

521

522

523

524

525

526

527

528

529

\section{References}

1001 Genomes Consortium. 2016. 1,135 Genomes Reveal the Global Pattern of Polymorphism in Arabidopsis thaliana. Cell 166:481-491.

Ågren J, Oakley CG, Lundemo S, Schemske DW. 2017. Adaptive divergence in flowering time among natural populations of Arabidopsis thaliana: Estimates of selection and QTL mapping. Evolution 71:550-564.

Ågren J, Oakley CG, McKay JK, Lovell JT, Schemske DW. 2013. Genetic mapping of adaptation reveals fitness tradeoffs in Arabidopsis thaliana. Proc Natl Acad Sci U S A 110:21077-21082.

Ågren J, Schemske DW. 2012. Reciprocal transplants demonstrate strong adaptive differentiation of the model organism Arabidopsis thaliana in its native range. New Phytologist 194:1112-1122.

Anderson JT, Willis JH, Mitchell-Olds T. 2011. Evolutionary genetics of plant adaptation. Trends Genet 27:258-266.

Baye TM, Abebe T, Wilke RA. 2011. Genotype-environment interactions and their translational implications. Per Med 8:59-70.

Beaumont MA, Balding DJ. 2004. Identifying adaptive genetic divergence among populations from genome scans. Mol Ecol 13:969-980.

Berardini TZ, Reiser L, Li D, Mezheritsky Y, Muller R, Strait E, Huala E. 2015. The Arabidopsis information resource: Making and mining the "gold standard" annotated reference plant genome. Genesis 53:474-485.

Berner D. 2019. Allele Frequency Difference AFD(-)An Intuitive Alternative to FST for Quantifying Genetic Population Differentiation. Genes (Basel) 10.

Bhatia G, Patterson N, Sankararaman S, Price AL. 2013. Estimating and interpreting FST: the impact of rare variants. Genome Res 23:1514-1521. 
Boissot N, Dutartre-Fricaux L, Beucher C, Vanlerberghe F. 2020. Highly conserved genes expressed in aphid saliva are candidates for host plant adaptation in Aphis gossypii. In: Research Square.

Brown SM, Heguy A, Zappile P, Chen H, Goradia A, Wang Y, Hao Y, Roy NK, Vitale K, Chambers RC, et al. 2017. A Dramatic Difference in Global Gene Expression between TCDDTreated Atlantic Tomcod Larvae from the Resistant Hudson River and a Nearby Sensitive Population. Genome Biology and Evolution 9:2251-2264.

Caye K, Jumentier B, Lepeule J, Francois O. 2019. LFMM 2: Fast and Accurate Inference of Gene-Environment Associations in Genome-Wide Studies. Mol Biol Evol 36:852-860.

Chiang GC, Bartsch M, Barua D, Nakabayashi K, Debieu M, Kronholm I, Koornneef M, Soppe WJ, Donohue K, De Meaux J. 2011. DOG1 expression is predicted by the seed-maturation environment and contributes to geographical variation in germination in Arabidopsis thaliana. Mol Ecol 20:3336-3349.

Cong L, Ran FA, Cox D, Lin S, Barretto R, Habib N, Hsu PD, Wu X, Jiang W, Marraffini LA, et al. 2013. Multiplex genome engineering using CRISPR/Cas systems. Science 339:819-823.

Cook D, Fowler S, Fiehn O, Thomashow MF. 2004. A prominent role for the CBF cold response pathway in configuring the low-temperature metabolome of Arabidopsis. Proc Natl Acad Sci U S A 101:15243-15248.

De Mita S, Thuillet AC, Gay L, Ahmadi N, Manel S, Ronfort J, Vigouroux Y. 2013. Detecting selection along environmental gradients: analysis of eight methods and their effectiveness for outbreeding and selfing populations. Mol Ecol 22:1383-1399.

de Villemereuil P, Frichot É, Bazin É, François O, Gaggiotti OE. 2014. Genome scan methods against more complex models: when and how much should we trust them? Molecular Ecology 23:2006-2019.

de Villemereuil P, Gaggiotti OE. 2015. A new FST-based method to uncover local adaptation using environmental variables. Methods in Ecology and Evolution 6:1248-1258.

Des Marais DL, Hernandez KM, Juenger TE. 2013. Genotype-by-Environment Interaction and Plasticity: Exploring Genomic Responses of Plants to the Abiotic Environment. Annual Review of Ecology, Evolution, and Systematics 44:5-29.

Des Marais DL, McKay JK, Richards JH, Sen S, Wayne T, Juenger TE. 2012. Physiological genomics of response to soil drying in diverse Arabidopsis accessions. Plant Cell 24:893-914. 
Dittmar EL, Oakley CG, Conner JK, Gould BA, Schemske DW. 2016. Factors influencing the effect size distribution of adaptive substitutions. Proc Biol Sci 283.

563

564

565

566

567

568

569

570

571

572

573

574

575

576

577

578

579

580

581

582

583

584

585

586

587

588

589

Exposito-Alonso M, Vasseur F, Ding W, Wang G, Burbano HA, Weigel D. 2018. Genomic basis and evolutionary potential for extreme drought adaptation in Arabidopsis thaliana. Nat Ecol Evol 2:352-358.

Foll M, Gaggiotti OE, Daub JT, Vatsiou A, Excoffier L. 2014. Widespread signals of convergent adaptation to high altitude in Asia and america. Am J Hum Genet 95:394-407.

Forester BR, Lasky JR, Wagner HH, Urban DL. 2018. Comparing methods for detecting multilocus adaptation with multivariate genotype-environment associations. Molecular Ecology 27:2215-2233.

Fournier-Level A, Korte A, Cooper MD, Nordborg M, Schmitt J, Wilczek AM. 2011. A map of local adaptation in Arabidopsis thaliana. Science 334:86-89.

Franssen SU, Gu J, Bergmann N, Winters G, Klostermeier UC, Rosenstiel P, Bornberg-Bauer E, Reusch TB. 2011. Transcriptomic resilience to global warming in the seagrass Zostera marina, a marine foundation species. Proc Natl Acad Sci U S A 108:19276-19281.

Gehan MA, Park S, Gilmour SJ, An C, Lee CM, Thomashow MF. 2015. Natural variation in the C-repeat binding factor cold response pathway correlates with local adaptation of Arabidopsis ecotypes. Plant J 84:682-693.

Gunther T, Coop G. 2013. Robust identification of local adaptation from allele frequencies. Genetics 195:205-220.

Hannah MA, Wiese D, Freund S, Fiehn O, Heyer AG, Hincha DK. 2006. Natural genetic variation of freezing tolerance in Arabidopsis. Plant Physiol 142:98-112.

Henry RJ, Nevo E. 2014. Exploring natural selection to guide breeding for agriculture. Plant Biotechnol J 12:655-662.

Hereford J. 2009. A quantitative survey of local adaptation and fitness trade-offs. Am Nat 173:579-588.

Hoban S, Kelley JL, Lotterhos KE, Antolin MF, Bradburd G, Lowry DB, Poss ML, Reed LK, Storfer A, Whitlock MC. 2016. Finding the Genomic Basis of Local Adaptation: Pitfalls, Practical Solutions, and Future Directions. Am Nat 188:379-397. 
Howe KL, Contreras-Moreira B, De Silva N, Maslen G, Akanni W, Allen J, Alvarez-Jarreta J, Barba M, Bolser DM, Cambell L, et al. 2020. Ensembl Genomes 2020-enabling non-vertebrate genomic research. Nucleic Acids Res 48:D689-D695.

Kawecki TJ, Ebert D. 2004. - Conceptual issues in local adaptation. - 7:- 1241.

Keller SR, Levsen N, Olson MS, Tiffin P. 2012. Local adaptation in the flowering-time gene network of balsam poplar, Populus balsamifera L. Mol Biol Evol 29:3143-3152.

Kelly M. 2019. Adaptation to climate change through genetic accommodation and assimilation of plastic phenotypes. Philos Trans R Soc Lond B Biol Sci 374:20180176.

Kinsella RJ, Kahari A, Haider S, Zamora J, Proctor G, Spudich G, Almeida-King J, Staines D, Derwent P, Kerhornou A, et al. 2011. Ensembl BioMarts: a hub for data retrieval across taxonomic space. Database (Oxford) 2011:bar030.

Lasky JR, Des Marais DL, Lowry DB, Povolotskaya I, McKay JK, Richards JH, Keitt TH, Juenger TE. 2014. Natural variation in abiotic stress responsive gene expression and local adaptation to climate in Arabidopsis thaliana. Mol Biol Evol 31:2283-2296.

Lasky JR, Des Marais DL, McKay JK, Richards JH, Juenger TE, Keitt TH. 2012. Characterizing genomic variation of Arabidopsis thaliana: the roles of geography and climate. Molecular Ecology 21:5512-5529.

López-Maury L, Marguerat S, Bähler J. 2008. Tuning gene expression to changing environments: from rapid responses to evolutionary adaptation. Nat Rev Genet 9:583-593.

Lotterhos KE, Whitlock MC. 2015. The relative power of genome scans to detect local adaptation depends on sampling design and statistical method. Mol Ecol 24:1031-1046.

Love MI, Huber W, Anders S. 2014. Moderated estimation of fold change and dispersion for RNA-seq data with DESeq2. Genome Biol 15:550.

Lovell JT, Schwartz S, Lowry DB, Shakirov EV, Bonnette JE, Weng X, Wang M, Johnson J, Sreedasyam A, Plott C, et al. 2016. Drought responsive gene expression regulatory divergence between upland and lowland ecotypes of a perennial C4 grass. Genome Res 26:510-518.

Luu K, Bazin E, Blum MG. 2017. pcadapt: an R package to perform genome scans for selection based on principal component analysis. Mol Ecol Resour 17:67-77.

Maddamsetti R, Hatcher PJ, Green AG, Williams BL, Marks DS, Lenski RE. 2017. Core Genes Evolve Rapidly in the Long-term Evolution Experiment with Escherichia coli. Genome Biol Evol. 
Matthey-Doret R, Whitlock MC. 2019. Background selection and FST : Consequences for detecting local adaptation. Mol Ecol 28:3902-3914.

McKhann HI, Gery C, Berard A, Leveque S, Zuther E, Hincha DK, De Mita S, Brunel D, Teoule E. 2008. Natural variation in CBF gene sequence, gene expression and freezing tolerance in the Versailles core collection of Arabidopsis thaliana. BMC Plant Biol 8:105.

Mee JA, Yeaman S. 2019. Unpacking Conditional Neutrality: Genomic Signatures of Selection on Conditionally Beneficial and Conditionally Deleterious Mutations. Am Nat 194:529-540.

Monroe JG, McGovern C, Lasky JR, Grogan K, Beck J, McKay JK. 2016. Adaptation to warmer climates by parallel functional evolution of CBF genes in Arabidopsis thaliana. Mol Ecol 25:3632-3644.

Monroe JG, Powell T, Price N, Mullen JL, Howard A, Evans K, Lovell JT, McKay JK. 2018. Drought adaptation in Arabidopsis thaliana by extensive genetic loss-of-function. Elife 7:e41038.

Morris MR, Richard R, Leder EH, Barrett RD, Aubin-Horth N, Rogers SM. 2014. Gene expression plasticity evolves in response to colonization of freshwater lakes in threespine stickleback. Mol Ecol 23:3226-3240.

Nielsen R. 2005. Molecular signatures of natural selection. Annu Rev Genet 39:197-218.

Nosil P, Funk DJ, Ortiz-Barrientos D. 2009. Divergent selection and heterogeneous genomic divergence. Mol Ecol 18:375-402.

Oakley CG, Agren J, Atchison RA, Schemske DW. 2014. QTL mapping of freezing tolerance: links to fitness and adaptive trade-offs. Mol Ecol 23:4304-4315.

Park S, Gilmour SJ, Grumet R, Thomashow MF. 2018. CBF-dependent and CBF-independent regulatory pathways contribute to the differences in freezing tolerance and cold-regulated gene expression of two Arabidopsis ecotypes locally adapted to sites in Sweden and Italy. PLoS One 13:e0207723.

Park S, Lee CM, Doherty CJ, Gilmour SJ, Kim Y, Thomashow MF. 2015. Regulation of the Arabidopsis CBF regulon by a complex low-temperature regulatory network. Plant J 82:193-207.

Postma FM, Lundemo S, Agren J. 2016. Seed dormancy cycling and mortality differ between two locally adapted populations of Arabidopsis thaliana. Ann Bot 117:249-256.

Price N, Lopez L, Platts AE, Lasky JR. 2020. In the presence of population structure: From genomics to candidate genes underlying local adaptation. Ecology and Evolution 10:1889-1904. 
Price N, Moyers BT, Lopez L, Lasky JR, Monroe JG, Mullen JL, Oakley CG, Lin J, Agren J, Schrider DR, et al. 2018. Combining population genomics and fitness QTLs to identify the genetics of local adaptation in Arabidopsis thaliana. Proc Natl Acad Sci U S A 115:5028-5033.

Purcell S, Neale B, Todd-Brown K, Thomas L, Ferreira MA, Bender D, Maller J, Sklar P, de Bakker PI, Daly MJ, et al. 2007. PLINK: a tool set for whole-genome association and population-based linkage analyses. Am J Hum Genet 81:559-575.

Razgour O, Forester B, Taggart JB, Bekaert M, Juste J, Ibanez C, Puechmaille SJ, NovellaFernandez R, Alberdi A, Manel S. 2019. Considering adaptive genetic variation in climate change vulnerability assessment reduces species range loss projections. Proc Natl Acad Sci U S A 116:10418-10423.

Rockman MV, Hahn MW, Soranzo N, Goldstein DB, Wray GA. 2003. Positive selection on a human-specific transcription factor binding site regulating IL4 expression. Curr Biol 13:21182123.

Savolainen O, Lascoux M, Merila J. 2013. Ecological genomics of local adaptation. Nat Rev Genet 14:807-820.

Seo E, Lee H, Jeon J, Park H, Kim J, Noh YS, Lee I. 2009. Crosstalk between cold response and flowering in Arabidopsis is mediated through the flowering-time gene SOC1 and its upstream negative regulator FLC. Plant Cell 21:3185-3197.

Thomashow MF. 2010. Molecular basis of plant cold acclimation: insights gained from studying the CBF cold response pathway. Plant Physiol 154:571-577.

Tiffin P, Ross-Ibarra J. 2014. Advances and limits of using population genetics to understand local adaptation. Trends Ecol Evol 29:673-680.

Trapnell C, Pachter L, Salzberg SL. 2009. TopHat: discovering splice junctions with RNA-Seq. Bioinformatics 25:1105-1111.

Trapnell C, Williams BA, Pertea G, Mortazavi A, Kwan G, van Baren MJ, Salzberg SL, Wold BJ, Pachter L. 2010. Transcript assembly and quantification by RNA-Seq reveals unannotated transcripts and isoform switching during cell differentiation. Nat Biotechnol 28:511-515.

Wollenberg Valero KC, Pathak R, Prajapati I, Bankston S, Thompson A, Usher J, Isokpehi RD. 2014. A candidate multimodal functional genetic network for thermal adaptation. PeerJ 2:e578.

Yeaman S. 2015. Local Adaptation by Alleles of Small Effect. Am Nat 186 Suppl 1:S74-89. 
681 Yoder JB, Stanton-Geddes J, Zhou P, Briskine R, Young ND, Tiffin P. 2014. Genomic signature 682 of adaptation to climate in Medicago truncatula. Genetics 196:1263-1275.

683 Yoder JB, Tiffin P. 2017. Effects of Gene Action, Marker Density, and Timing of Selection on 684 the Performance of Landscape Genomic Scans of Local Adaptation. J Hered 109:16-28.

685 Zhen Y, Dhakal P, Ungerer MC. 2011. Fitness benefits and costs of cold acclimation in 686 Arabidopsis thaliana. Am Nat 178:44-52.

687 Zhen Y, Ungerer MC. 2008a. Clinal variation in freezing tolerance among natural accessions of 688 Arabidopsis thaliana. New Phytol 177:419-427.

689 Zhen Y, Ungerer MC. 2008b. Relaxed selection on the CBF/DREB1 regulatory genes and 690 reduced freezing tolerance in the southern range of Arabidopsis thaliana. Mol Biol Evol 25:25476912555.

692 Zhou X, Stephens M. 2012. Genome-wide efficient mixed-model analysis for association 693 studies. Nat Genet 44:821-824. 